\title{
8
}

\section{im

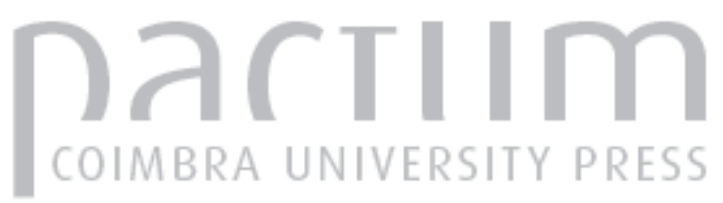

\section{[Recensão a] Miguel CISNEROS CUNCHILOS, Marmoles Hispanos: Su Empleo en la Espana Romana}
Autor(es):
D'Encarnação, José

Publicado por: Imprensa da Universidade de Coimbra

URL persistente:

URI:http://hdl.handle.net/10316.2/45557

DOI:

DOI:https://dx.doi.org/10.14195/1647-8657_29_15

Accessed : $\quad$ 26-Apr-2023 13:05:03

A navegação consulta e descarregamento dos títulos inseridos nas Bibliotecas Digitais UC Digitalis, UC Pombalina e UC Impactum, pressupõem a aceitação plena e sem reservas dos Termos e Condições de Uso destas Bibliotecas Digitais, disponíveis em https://digitalis.uc.pt/pt-pt/termos.

Conforme exposto nos referidos Termos e Condições de Uso, o descarregamento de títulos de acesso restrito requer uma licença válida de autorização devendo o utilizador aceder ao(s) documento(s) a partir de um endereço de IP da instituição detentora da supramencionada licença.

Ao utilizador é apenas permitido o descarregamento para uso pessoal, pelo que o emprego do(s) título(s) descarregado(s) para outro fim, designadamente comercial, carece de autorização do respetivo autor ou editor da obra.

Na medida em que todas as obras da UC Digitalis se encontram protegidas pelo Código do Direito de Autor e Direitos Conexos e demais legislação aplicável, toda a cópia, parcial ou total, deste documento, nos casos em que é legalmente admitida, deverá conter ou fazer-se acompanhar por este aviso.

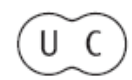


FACULDADE DE LETRAS

INSTITUTO DE ARQUEOLOGIA

CONIMBRIGA

VOLUME XXIX

UNIVERSIDADE DE COIMBRA

1990 
Iulius Longinus Doles, da Ala Tartorum Victrix Civium Romanorum. Trata-se, de facto, duma das raras referencias a trácios na epigrafía da Península Ibérica e Patrick Le Roux \{L'Armée Romaine et l'Organisation des Provinces Ibériques d'Auguste à l'Invasion de 409, Paris, 1982, p. 87 n. 34 e p. 216 n. ${ }^{\circ}$ 157) teve ocasião não só de justificar a presença dessa ala na Península Ibérica, possivelmente desde 68 ao fim do século I, como de confirmar a origem tràcia deste eques. Doles não seria, pois, como à primeira vista poderia parecer, um caso de omissão do $n$ antes de $s$ (cf. CIL II, p. 1189) e dever-se-á ter em atenção esse facto ao repensar CIL II 6, onde propus somente a leitura Teia Dole[ns7] (IRCP 27).

$\mathrm{O}$ uso da pontuação entre consoantes duplas na inscrição 52 (pp. 123-124) é justificado por Anna Illuminati, na sequência de Schulze, como sendo uma forma de, assim, se realçar a exactidão da grafia. Cita-se, a propósito, CIL II 4085, de Tarragona. Já os exemplos que pude colher na epigrafia do conventus Pacensis (IRCP, p. 880) não permitem, porém, essa conclusão: textos há que apresentam interpunctio mas não nas consoantes duplas.

De interesse, ainda, a referência à omissão do $i$ na forma verbal posivit - posiut que se regista no n. ${ }^{\circ} 112$ (pp. 194-195). As autoras consideram ser um "perfeito sincopado" e aduzem outros exemplos, entre os quais CIL II 6302, de Palência. A circunstância de essa epígrafe apresentar tantas anomalias ortográficas levar-nos-ia a pensar, de preferência, num erro quer de omissão quer de troca de letras (posiut por posuit). Assim o julgaria, de facto, se não houvesse tais exemplos.

É, evidentemente, a permanente troca de informações que permite o avanço da Ciência, designadamente duma ciência como a Epigrafia que se alicerça em vasta documentação esparsa por todo um Império. Bons e completos índices constituem, por isso, instrumento de trabalho imprescindível. Daí que o volume ora em apreço deva ser, doravante, ponto de referência obrigatório.

JosÉ DENCARNAÇÃo

Miguel CISNEROS CUNCHILOS, Marmoles Hispanos: Su Empleo en la Espana Romana.

Departamento de Ciencias de la Antigüedad, Universidad de Zaragoza, 1988.

ISBN: 84-600-7010-7. 200 páginas.

A oportunidade da obra de Miguel Cisneros Cunchillos resulta incontestável:

1) porque o estudo da proveniência dos mármores usados na escultura, na arquitectura e na epigrafia faculta preciosas informações no dominio da historia da ocupação romana peninsular;

2) porque, sendo uma síntese da sua dissertação de doutoramento, Marmoles $y$ Otras Rocas Explotadas en la España Romana, defendida nesse mesmo ano (1988) na Universidade de Zaragoza, apresenta com clareza, concisão e arguto poder de análise, toda a problemática que envolve a exploração, comercialização e utilização do mármore durante a Antiguidade Clássica.

Como Manuel Martín-Bueno escreve no prólogo de apresentação do livro, uma investigação sobre o mármore ultrapassa hoje "o âmbito próprio dos estudos sobre técni-

Conimbriga, 29 (1990), 147-194 
cas extractivas, recursos mineiros ou simples especulações sobre as cadeias de produção e comercialização daqueles produtos pelos antigos" (p. 15).

De facto, Miguel Cisneros Ganchillos assim fez. E se, em qualquer obra, a leitura da introdução sempre se reveste de interesse para ajuizarmos da forma como o autor encarou o tema, aqui essa leitura é deveras primordial, dado que aí se apontam os problemas em aberto, a metodologia usada para os abordar e os resultados obtidos.

Salienta Miguel Cisneros Cunchillos, por exemplo, que um estudo deste género passa - não há dúvida - pela identificação do material mas que não se deverá quedar por aí, pois há que detectar, através dele, os "factores económicos e sociais inerentes ao próprio material, aos seus utilizadores e aos operários” (p. 19).

Nesse sentido e após uma preliminar pesquisa bibliográfica (referências aos mármores hispânicos nas fontes literárias clássicas e posteriores), o autor recolheu as informações fornecidas pelos documentos epigráficos acerca da existência de oficinas lapidares; analisou os dados já contidos, a este respeito, em obras da especialidade (quer gerais quer específicas); e cotejou, finalmente, todos esses elementos com os que pessoalmente obteve na pesquisa de campo e na demorada visita a museus.

O tema fulcral do estudo são os mármores procedentes de pedreiras sitas no que Miguel Cisneros Cunchillos designa por sectores "andaluz", na Cordilheira Bética, e "estremenho-português", no chamado Maciço Hespérico. E a razão desta escolha resulta evidente do facto de serem estas duas zonas aquelas sobre que, na realidade, maior acervo documental se dispõe.

De resto, a caracterização dos diferentes tipos de mármores explorados ao tempo dos Romanos e a localização geográfica das pedreiras é feita logo. na introdução: os núcleos almeriense e malaguenho da Cordilheira Bética (pp. 22-25); e os da metade ocidental da Península, estremenho e português (pp. 25-28). A observação atenta dos quadros inseridos no apêndice I, sobre as características petrográficas dos mármores em apreço, completa eficazmente esses dados.

Dos mármores portugueses usados pelos Romanos refere Miguel Cisneros Cunchillo os cinzentos de Pardais, os brancos e rosados de Estremoz-Vila Viçosa e Borba, e os verdes de Viana do Alentejo. As suas fontes de informação foram, sobretudo, o volume I das Fouilles de Conimbriga (Paris, 1977, pp. 271-276), onde António Tavares dá conta dos mármores utilizados naquela cidade romana, e o meu trabalho Inscrições Romanas do Conventus Pacensis ( = IRCP) (Coimbra, 1984, pp. 821-822), em que sintetizei a traços largos o que rastreei acerca do material usado na epigrafia romana do conventus. Não pôde Miguel Cisneros Cunchillos visitar com vagar os museus portugueses; pelo menos, nenhum museu português é incluído na Usta referida na p. 29. Compreende-se a dificuldade; de qualquer modo, uma ida ao Museu Nacional de Arqueologia, em Lisboa, e, de modo especial, ao Museu Regional de Beja ter-lhe-ia permitido familiarizar-se com o chamado "mármore de Trigaches" ou "de São Brissos", a que alude na p. 77 sem pormenorização das suas características. O Portugal Romano de Jorge de Alarcão (na sua 1. ${ }^{\text {a }}$ edição, Lisboa, 1974) foi também consultado e dele se extraíram breves informações. Ora, quer se considere o termo mármore na sua acepção restritamente geológica — rocha calcária que sofreu longas acções de metamorfismo - quer, mais genericamente, como rocha ornamental, tanto as lumachelas cretássicas ou brechas rosadas e conquíferas da Arrábida (Setúbal) como os mármores rosas e vermelhos de Lameiras (Sintra), como os também rosados de São Domingos de Rana (Cascais) teriam de ser incluídos, pois a sua utilização, 
por exemplo, para o fabrico de monumentos epigráficos se encontra assaz documentada: cf., para as lumachelas da Arrábida, a maior parte dos monumentos epigráficos de Tróia (IRCP, pp. 277-290); e, para os de Sao Domingos de Rana, as epígrafes inseridas, em 1983 e 1985, no "Ficheiro Epigráfico" (Coimbra), sob os números 24 e 59, respectivamente. Já quanto à inserção da pedra de Ançã e do calcário de Porto de Mós neste contexto (p. 80), eu hesitaria um pouco mais. O seu uso na epigrafía, na escultura e mesmo na arquitectura da época romana não pode sofrer contestação, mas é praticamente inexistente o seu metamorfismo: são calcários simples e, por isso, optaria por não os incluir numa obra sobre mármores, como se não inclui o granito ou o xisto.

No I capítulo, "Fuentes", estudam-se as fontes literárias clássicas (pp. 37-43), as epigráficas (pp. 44-54) e as referencias literárias desde o século XII ao XIX (p. 54 e fig. 3).

Capítulo importante é, deveras, o II — "Referências arqueológicas" (pp. 57-84) - que vai ilustrado com um mapa de localização das pedreiras. Aí se concretizam, de forma clara, por províncias e por conventus, os dados disponíveis acerca da existência de pedreiras, discutindo-se, a propósito, as teses já apresentadas pelos diversos autores, designadamente por Alicia M. CANTO, cujo trabalho Avances sobre la explotación del mármol en la España romana ("Archivo Español de Arqueología” 50-51 1977-1978 165-189) terá decerto marcado, apesar das suas compreensíveis deficiências, o arranque destes estudos a nivel peninsular.

Particular atenção merece, tanto neste capítulo (pp. 76-77) como no anterior (p. 51), a problemática relacionada com as pedreiras de Almadén de la Plata, designadamente no que respeita ao seu estatuto jurídico-administrativo: dependência directa do imperador ou, apenas, do governador senatorial da provincia da Bética em que se localizam? O autor, embora não ouse dar-lhe uma resposta definitiva (p. 134), parece, de facto, inclinar-se para a segunda hipótese.

Em meu entender, o estatuto previsto na legislação de Vipasca para as diferentes actividades aí desenvolvidas poderia ter sido aqui evocado com toda a propriedade, tanto mais que aí se fala, a dado passo (IRCP 142, § 7, Unha 54), das "lapides lausiae expeditae in lapicaedinis", ou seja, das "lousas já preparadas nas pedreiras", precisamente no capítulo que trata dos contratos dos negociantes de escórias e de pedra. Foi, decerto, um dado que terá escapado a Miguel Cisneros Cundidlos, porque me parece, na verdade, muito passível de se aplicar aqui o esquema previsto para Vipasca: essa exploração é da exclusiva jurisdição imperial, pertence ao Estado, que a adjudica em hasta pública ao arrendatário que melhores garantias oferecer. Cf., a propósito desta passagem: Claude DOMERGUE, La mine antique d'Aljustrel (Portugal) et les tables de bronze de Vipasca, "Conimbriga" 221983 95-97.

Elenca o capítulo III os mármores espanhóis e portugueses utilizados e aí se especifica como e quando o foram, dados que se sistematizam no exaustivo e bem elaborado inventário inserido no apêndice II (pp. 149-170). Conclui Miguel Cisneros Cundidlos que os mármores da zona almeriense foram usados na arquitectura, em obras escultóricas e em monumentos epigráficos desde a época dos júlios-cláudios até ao século II da nossa era; os da zona malaguenha também se empregaram nos mesmos domínios e, genericamente, na mesma época, embora possa haver indícios da exploração do mármore de Honda já na segunda metade do século II a. C.; os mármores estremenhos foram preferidos para a arquitectura e para a epigrafia, também no Alto Império; as pedreiras de Almadén de la Plata, exploradas no Alto Império também, forneceram, de modo especial, 
elementos arquitectónicos; e, por fim, os mármores do actual Alentejo português têm uma utilização que vai do século I ao IV nos domínios arquitectónico, escultórico e epigráfico.

Finalmente, o capítulo IV aborda as questões relacionadas com o comércio e o transporte. De novo se considera como os Romanos privilegiaram as rotas marítimas e fluviais, designadamente o Ebro e o Guadalquibir. Discute Miguel Cisneros Cunchillos o problema do escoamento dos mármores de Estremoz-Vila Viçosa, por exemplo, até à capital de província onde a sua presença se encontra bem documentada: a possibilidade de um transporte directo por via terrestre, dadas a relativa pequena distância entre as pedreiras e Mérida e a escassa navegabilidade do rio Guadiana, é hipótese que se lhe afigura preferível à alternativa da ida até a um porto da costa meridional subindo depois o Guadalquibir, em cujo curso médio poderá ter existido, no entanto, um centro de armazenamento e distribuição (p. 128).

As pp. 131-139 sintetizam eloquentemente o conteúdo da obra, que é completada com índices de fontes literárias clássicas, de inscrições, de figuras; e com a bibliografia.

O livro vem na sequência da investigação desenvolvida desde há longos anos quer, pontualmente, em Conímbriga quer, sobretudo e de forma sistemática, nos laboratórios especializados adscritos às universidades espanholas. Estou a recordar o Laboratório de Petrología del Area de Petrología y Geoquímica de la Universidad de Zaragoza, expressamente citado nesta obra (p. 29, n. 42) e a actividade desenvolvida nesse sentido pelo Departamento de Cristalografia e Mineralogia da Universidade Autónoma de Barcelona, em colaboração com o Prof. Marcos Mayer, que tem a seu cargo a coordenação dessa investigação com vista à reedição do II volume do Corpus Inscriptionum Latinarum. Parece-me, pois, que a mais estreita colaboração peninsular num projecto comum colherá, decerto, sólidos resultados, sem necessidade de procedermos também nós, portugueses, à criação de equipamento laboratorial próprio mais sofisticado - intenção que me pareceu poder deduzir da posição veiculada por Manuel Justino Maciel e Helder Coutinho, na comunicação que apresentaram, em Abril de 1990, ao II Colóquio Arqueológico de Viseu, subordinada ao título $A$ utilização dos mármores em Portugal na época romana: ensaio de uma metodologia de estudo.

Curiosamente, Miguel Cisneros Cunchillos sentiu-se na obrigação de justificar a inserção, ainda que não exaustiva (p. 109), no seu trabalho, dos mármores portugueses. Alegou razões de ordem geológica e a grande utilização que eles tiveram em Mérida (p. 108). Seria, de facto, bem estranho que assim não tivesse procedido - mas essa sua justificação veio acentuar o interesse de rapidamente se eliminarem, no domínio científico, as fronteiras nacionais.

Uma palavra ainda acerca do I capítulo. É que, se os testemunhos arqueológicos são — de longe! - neste caso os mais expressivos, não é menos verdade que as referências literárias assumem o maior significado por serem expressão pública duma realidade palpável, importante, e os textos epigráficos constituem prova cabal da existência duma actividade minimamente organizada.

Pertence a Plínio, na Naturalis Historia, III, 3, 30, a única referência literária expressa à exploração marmórea numa península onde a extracção de minérios (de ouro, prata, cobre e ferro) pesava muito mais significativamente na balança económica imperial. Daí - como Miguel Cisneros Cunchillos bem assinala (p. 41) - a quase inexistência de alusões concretas. Além de se referir ao lapis specularis, o gesso selenitico dos arredores de Segobriga (p. 39), fala de marmorum lapicidinae, de pedreiras de mármore na Hispânia. 
As fontes epigráficas permitem-nos detectar o funcionamento de oficinas, como a de Flavus de Conimbriga (p. 45) e mencionam, por vezes, quem trabalha com o mármore: os marmorarii (IRCP 269 e 497) e os lapidarii. Quanto a estes últimos, cita Miguel Cisneros Cunchillos quatro inscrições: a de Caldas de Vizela (CIL II 2404), a de Peñalba de Castro (CIL II 2772), urna de Elvas e outra de Cartagena (p. 51) Esse texto dado corno procedente de Elvas pela Hispania Antiqua Epigraphica 1520 é, porém, de Afife, no conventus bracaraugustanus: cf. Vi AN A (Abel), Um "lapidarius" de Afife (Viana do Castelo), "Crónica del III Congreso Arqueológico Nacional (Galicia, 1953)”, Zaragoza, 1955, pp. 525-528; por outro lado, a reconstituição ai proposta por Abel Viana - [LAJPIDARIVS deve ser encarada corn sérias reservas, dadas as suas inusitadas características. Desta forma, resulta sem significado a justificação dada pelo autor na p. 51 e, a existir a referência a um lapidarius, a sua actividade estaria decerto ligada à abundância de clientela, razão que também se invoca para a presença de Reburrino junto ao local de culto às Ninfas Castecas (CIL II 2404, já citado), comentada por Miguel Cisneros Cunchillos na p. 53.

Além das citadas referências a trabalhadores da pedra, duas outras se poderão aduzir. A primeira foi dada a conhecer por Alain Tranoy (Ateliers lapidaires et niveaux de culture dans le Nord du Portugal, "Gallaecia" 7/8 1984 269-274): na parte superior duma ara a I. O. M., descoberta em Santa Cruz de Lima (Ponte de Lima), lê aquele investigador EX. OF(flicina) ELP(IDI?). Numa escultura funerária de S. Tomé de Vade, concelho de Ponte da Barca, no conventus bracaraugustanus também, ainda inédita mas já referida por Jorge de Alarcão no seu Roman Portugal (vol. II, fase. 1, p. 5, n. ${ }^{\circ}$ 1/82, foto 111), lê-se no final ARCIVS FECIT, donde se pode deduzir a identificação dum escultor e lapidàrio, dono decerto de uma oficina local.

E se a redacção do primeiro parágrafo da p. 52 se me afigura um pouco confusa, por não destrinçar claramente quem se identifica com os tria nomina e os trabalhadores que apenas usam um nome, também gostaria de informar que Jorge de Alarcão e António Tavares estudaram pormenorizadamente, na sequência da visita de estudo que ali fizeram em Junho de 19-76, os vestígios da exploração romana de mármore identificados na Herdade da Vigária, junto a Vila Viçosa, aos quais o autor se refere, por exemplo, na p. 78. O texto do citado estudo foi inserido no vol. II (pp. 1-12) dos "Studia Pompeiana \& Classica - in honour of Wilhelmina F. Jashemski", editado por Robert I. Curtis (New York, 1989) sob o título A Roman Marble Quarry in Portugal. A exploração pôde ser datada através do achamento dum fragmento de vaso de terra sigillata sudgálica com a marca GEMINV(s), oleiro que trabalhou ao tempo dos Flávios (ibidem, p. 6). Perguntam os autores se o baixo-relevo representa "an attempt to depict a nymph, a virile divinity, the god Fontanus, or the goddess Fontana" (ibidem). A sugestão destas duas últimas divindades reside na circunstância de se ter achado nas proximidades, em Bencatel, uma ara dedicada a este par divino (IRCP 438). A problemática das técnicas de exploração são também abordadas no artigo, uma vez que no local se detectaram as marcas para o corte dos bancos de mármore.

Está Miguel Cisneros Cunchillos a especializar-se num domínio que se apresenta, a todos os títulos, de importância fundamental para a reconstituição do que foi a vida económica peninsular ao tempo da dominação romana. A metodologia adoptada é a correcta, as conclusões cautelosas mas seguras. E este livro constitui, sem dúvida, um marco indispensável para as futuras pesquisas a fazer.

JOSÉ d'ENCARNAÇÃO 
Luis Alberto LÓPEZ PALOMO, Janine LANCHA e André DAVIAUlt, Un mosaico con inscripciones - Puente Genii (Cordoba). Publications de la Casa de Velázquez, Série Études et Documents, III. Madrid, 1987. 84 pp., ilustr. ISSN: 0213-1803.

Este livrinho apresenta, logo à partida, duas originalidades. A primeira, o seu rigoroso bilinguismo, texto espanhol à esquerda, texto francês na coluna da direita. Depois, a importância dada ao minucioso estudo dum mosaico legendado.

De facto, pelo que sei, talvez seja esta a primeira vez que um mosaico se constitui objecto de trabalho monográfico assinado por três especialistas diferentes: um arqueólogo, Luis Alberto López Palomo, dá conta das circunstâncias do achado e enquadra-o no seu contexto histórico e geográfico; Janine Lancha faz o estudo arqueológico do mosaico e analisa a iconografia das suas representações; por fim, André Daviault, professor de Literatura Latina na Universidade Laval, do Quebeque, teve a seu cargo a apreciação da inscrição do ponto de vista filológico e literário. Uma pluridisciplinaridade que se realça e desde já se aponta como exemplo a imitar.

A villa romana donde o mosaico proveio situa-se numa localidade chamada Fuente Alamo, no termo do município espanhol de Puente Genii, província de Córdoba (Andaluzia). López Palomo descreve miudamente as características geográficas do sítio, o ambiente arqueológico em que se integra, o seu significado histórico. Conta, depois, como se processou a escavação que, em 1982, esteve na origem do levantamento do mosaico, hoje depositado no Museu Arqueológico Provincial de Córdoba.

Foi preocupação de Janine Lancha apresentar minuciosa visão do monumento: a sua técnica de execução, os aspectos formais de cada uma das figuras, as legendas, as questões estilísticas, a iconografia. (Anote-se, de passagem, a troca das figuras 6 e 7, na pág. 25). Conclui a investigadora que estaifios seguramente "perante a versão literária original dum dos mais antigos e duradouros temas iconográficos greco-romanos, a 'nanomaquia', apresentada numa forma teatral que não permite dúvidas” (p. 52).

É, porém, nas legendas que radica o maior interesse do mosaico de Puente Genii.

"Outra vez inscrições sobre um mosaico!", afirmam os autores que Jean-Nod Bonneville exclamara, aquando da descoberta do mosaico. E ao mesmo tempo que, mediante o seu estudo, evocam a memória do companheiro saudoso e do epigrafista sagaz, vão demonstrar como, de facto, a sua exclamação tem razão de ser. Primeiro, porque a descoberta de textos em mosaicos se toma cada vez mais frequente; depois, porque todos eles se revestem habitualmente de não pequenas dificuldades de interpretação e, inclusive, de leitura.

Constitui o estudo da inscrição o capítulo III desta obra, dividido em duas partes: procura-se, na primeira (pp. 55-69), estabelecer o texto e proceder à sua análise, de forma a detectar o que André Daviault designa vis comica das presentes inscrições; é dedicada a segunda ao confronto do texto com a literatura dramática, confronto que parece poder sugerir a hipótese de estarmos perante "novos fragmentos de um mimo latino" (pp. 69-78).

Datável do século IV, a legenda do mosaico de Puente Genii será, pois, a ressonância dum texto literário antigo, ressonância que- é alarde e ressurreição, mais um índice, portanto, do retomo ao glorioso passado mitológico e clássico duma Roma ora ameaçada pelos Bárbaros nas suas estruturas políticas e pelas influências cristãs nas suas estruturas culturais.

Mas vejamos concretamente o texto em causa.

$\mathrm{Na}$ primeira cena, o pigmeu atacado pela grua tem atrás de si a legenda SV CERBIO, que foi interpretada como "sum Cervius", "sou Cèrvio", forma original de se apre-

Conimbriga, 29 (1990), 147-194 
sentar ao visitante, em vez da simples e estereotipada menção do nome. A frase que encima o grupo E FILI GERIO VALE é pedido de socorro, como quem diz "ó filho, Gerião, acode-me !". Ao que o filho, armado de bastões, a correr, lhe responde, batendo na grúa, SVBDVC TE PATER, "ó pai, tira-te daí debaixo!". De cabelos soltos, apresada também, a mãe, identificada como VXOR MASTALE, "a mulher mamalhuda", grita AI MISERA DECOLLATA SO, "Ai pobre de mim, estou decapitada!".

A cena da ábside $n .^{\circ} 2$ representa o final feliz. A ave é puxada por um pigmeu que parece dizer ET TV ERE SVMA. André Daviault interpreta ERE como o vocativo de erus, senhor; e suma, o imperativo de sumere, agarrar. E traduz: "E tu, senhor, agarra!" Creio que esta interpretação é demasiado forçada. Prefiro ver em ERE uma forma popular de ERAS, segunda pessoa do singular do pretérito imperfeito do verbo esse e traduzir: "E eras tu enorme!". A frase teria um sentido depreciativo - como quem ironiza "E agora estás reduzida a nada" - e seria simultaneamente uma expressão de alívio, "caramba que ela era bem grande!" Por isso, a figura que, de pé, acompanha a cena, porventura o "Cèrvio" que dela, enfim, se livrara, acrescenta E IMPORTVNA, "E importuna!", recordando o mau bocado por que passara. A omissão do T (de ET) parece-me muito mais verosímil e frequente que ver aí a interjeição HEM, de carácter mais literário que epigráfico.

Por fim, à terceira personagem que, com um bastão, empurra a ave, é atribuída a frase TIMIO NE VECTI FRANGA, equivalente, como afirma André Daviault, a timeo ne vectim frangam, "tenho medo de partir a vara".

A sequência - como eu a concebo - é a seguinte: quem carrega com o peso morto, suspira "bolas, que isto pesa!"; quem se viu atacado, só se lembra é de como foi importunado; o outro, a quem também incumbe um esforço físico, volta à ideia inicial de peso.

Quanto à terceira legenda-SELVAM/GRAVE[M7] — ela pode, na verdade, vir na sequência das anteriores, indicando o local (o "bosque") para onde se desejaria levar a presa; o vocábulo gravis, "pesado", retomaria o pensamento patente na ábside n. ${ }^{\circ} 2$. Concordo que essa é, porém, "frágil suposição" (p. 69).

Com base em dados literários e filológicos, que minuciosamente escalpeliza, pretende André Daviault ver aqui o reflexo dum mimo teatral, apresentado pelo proprietário da villa precisamente no triclinium da sua domus para divertir os convidados. A vis comica, ou seja, a comicidade do conjunto resultaria, em seu entender, não tanto da representação clássica, mais ou menos usual, do combate entre os pigmeus e uma grúa, mas sim da nomenclatura atribuída às personagens intervenientes. Gerion, nome de forçudo e musculado gigante, identifica agora um disforme anão desajeitado. André Daviault aproxima o suposto nome do pai do antropònimo Cervius, que relaciona etimologicamente com "cervix", cabeça. O lamento da mulher teria, desta sorte, pleno cabimento, porque, ao perder o marido, ficava... "decapitada" - e, num contexto de comédia, a frase não deixaria de provocar risada. Finalmente, André Daviault analisa o significado do nome Mastale, muito provável latinização "duma palavra grega feminina derivada de /uaarós, "mama' " que se aproxima, portanto, do vocábulo latino mammeata, "a que tem as mamas grandes" (p. 59) - o que, tendo em conta a generosa representação dos seios, sublinharia, em seu entender, o carácter humorístico do nome.

Não nego o grande interesse das pistas ora traçadas pela bem documentada investigação de André Daviault. Creio, no entanto, que talvez nos possamos ater a explicações mais singelas e mais consentâneas, quiçá, com o carácter popular (e, por isso mesmo, 
nada erudito) de que habitualmente se reveste a linguagem patente ñas legendas dos mosaicos.

Assim, a identificação na primeira pessoa é deveras artificial, para já se não falar da dificuldade em fazer equivaler Cerbio a Cervius. Não seria mais lógico vislumbrar aí, por exemplo, a forma servio, "estou preso"? A grua prende-lhe, de facto, o braço com o bico. Su poderá ser sum, "eu sou", mas também não será de rejeitar a hipótese de ver aí a interjeição sus $\backslash$ A sequência seria: o pai incita o filho, porque está a ser atacado pela grua e o filho vai tirá-lo de sob as garras do animal: subduc te pater

Da representação exagerada dos órgãos sexuais dos anões e dos seios da mulher não se toma obrigatório deduzir qualquer outra intenção, burlesca, por exemplo, para além da que é habitual em circunstâncias idênticas. Assim se costumam representar os anões e também outra não seria a posição da mulher em corrida, levemente inclinada para diante.

Num hilariante misto de tragédia e comédia — o riso que sobrevém à semi-asfixia do perigo eminente - , a cena patenteada no mosaico de Puente Genii não deixa de claramente ilustrar, como sublinha André Daviault, "a influência do teatro cómico sobre a iconografia dos pigmeus, ao mesmo tempo que manifesta, para além disso, o facto de o repertório das antigas comédias ainda manter, pelo menos através das personagens intervenientes, uma autêntica vis comica". Estamos de acordo. É, como atrás dizia, o século IV, o ressurgir da temática tradicional, a vontade de segurar, pela cultura, um poder que pelas outras vias, impertinentemente, fatalmente, teimava em querer escapar-se-lhes. É nesse sentido, aliás, que se deve interpretar a frase com que Janine Lancha termina a sua análise - arqueológica e iconográfica — do mosaico em questão:

"Nanomaquia de sabor burguês, prazer verbal e paixão pela caricatura - tudo ideias da nova leitura de antigas imagens feita por um escol na Hispânia romana, no decorrer do século IV" (p. 54).

E não podemos deixar de recordar, a propósito, a célebre cena patente no mosaico de Santa Vitória do Ameixial. Aí, o aspecto também é de suprema seriedade. À primeira vista, um homem fustiga a mulher nua, dobrada sobre si mesma no secreto de minorar a dor da vergastada. Ambiente pesado e tenso, dir-se-á, impróprio até duma área termal supostamente propícia à descontracção, ao repouso, às doçuras corporais... Mas, tal como em Fuente Alamo, é pela legenda que vai perpassar a aragem desanuviante: "Felicião, escaldado, é pior que um carroceiro!” E lá estava representado, de pé, altivo, Felicião façanhudo, Felicione misso. "Admoestação assaz realista e solene, feita eventualmente pelo proprietário da villa, ao seu pessoal no capítulo disciplinar: as faltas, de qualquer ordem, são severamente punidas - como, aliás, a cena demonstrava e as legendas acentuavam aludindo às fúrias de Felicião", escrevi em 1984 (IRCP, p. 559). Todavia, qual dos convivas do senhor resistiria a esboçar um largo sorriso quando, ao pisar, descontraído, o chão da sala, se lhe deparasse, inopinada, a cena? Em Fuente Alamo, era o anão a estar na mó de baixo e a ser resgatado no derradeiro momento por outro anão com nome de gigante; em Santa Vitória do Ameixial, a desleixada escrava a tremer sob terrificantes vergastadas. Num e noutro, o riso a brotar, irónico, duma possibilidade de desgraça.

P.S.: O texto vem referido em AE 1987 501. Contrariamente ao que lhe é habitual, o responsável, na revista, pelos comentários aos estudos epigráficos peninsulares parece não ter querido usar, aqui, do seu espírito crítico, uma vez que transcreve (inusitadamente sem objecções) a proposta interpretativa dos editores.

\section{JOSÉ dTNCARNAÇÃO}

